\title{
Review Article \\ Therapy Effects of Bone Marrow Stromal Cells on Ischemic Stroke
}

\author{
Xinchun Ye, Jinxia Hu, and Guiyun Cui \\ Department of Neurology, The Affiliated Hospital of Xuzhou Medical College, Xuzhou, Jiangsu Province 221006, China
}

Correspondence should be addressed to Guiyun Cui; guiyuncui@foxmail.com

Received 8 January 2016; Accepted 25 February 2016

Academic Editor: Ryuichi Morishita

Copyright (C) 2016 Xinchun Ye et al. This is an open access article distributed under the Creative Commons Attribution License, which permits unrestricted use, distribution, and reproduction in any medium, provided the original work is properly cited.

Stroke is the second most common cause of death and major cause of disability worldwide. Recently, bone marrow stromal cells (BMSCs) have been shown to improve functional outcome after stroke. In this review, we will focus on the protective effects of BMSCs on ischemic brain and the relative molecular mechanisms underlying the protective effects of BMSCs on stroke.

\section{Introduction}

Stroke is the second most common cause of death and major cause of disability worldwide [1]. Current therapies of stroke target angiogenesis, neurogenesis, and oligodendrogenesis to attenuate brain tissue damage from ischemic injury and improve neurological outcome. However, the only globally approved drug for acute ischemic stroke is tissue plasminogen activator (tPA), but it must be given within $4.5 \mathrm{~h}$ after stroke onset [2]. Thus, the beneficial effect of tPA is limited to a narrow therapeutic window.

Recently, many other agents have provided promising approaches for stroke patients beyond the hyperacute phase in clinical trials. Statins used to lower circulating cholesterol levels have been shown to possess neurorestorative properties, increase angiogenesis and neurogenesis after stroke, and improve functional recovery [3]. Niaspan, primarily used to provide vitamin $\mathrm{B} 3$, has also been shown to reduce blood-brain barrier (BBB) leakage and improve neurological outcome and vascular remodeling after stroke $[4,5]$.

Cell-based therapy is a promising approach to promote functional recovery after stroke [6]. Bone marrow stromal cells (BMSCs) treatment of stroke has been shown to enhance function recovery, ameliorate cognitive dysfunction, and improve neuroplasticity by regulating neurogenesis, angiogenesis, and oligodendrogenesis [7-12].

This review will focus on the characteristics of BMSCs treatment for stroke and molecular mechanisms of neurorestorative effects of BMSCs on ischemic stroke.

\section{Identification and Characteristics of Bone Marrow Stromal Cells}

Stem cells were firstly isolated from bone marrow (BM) in 1960s, characterized by both their rapid adherence to plastic and their fibroblast-like morphology [13]. It was examined in the laboratory that the BMSCs contain many subsets, including hematopoietic stem cells (HSCs), mesenchymal stem cells (MSCs), endothelial progenitor cells (EPCs), and very small embryonic-like stem cells (VSELs) [14-16]. BMSCs express a number of nonspecific markers as CD105 (SH2), CD73 (SH3/4), CD44, CD90 (Thy-1), CD71, and Stro-1, as well as the adhesion molecules CD106 and CD166, intercellular adhesion molecule1, and CD29 [17].

BMSCs are characterized with paracrine actions, immunomodulation, and multipotency [18-20]. The neurotrophic effects of BMSCs, releasing growth and trophic factors or stimulating their release from resident brain cells, have been suggested to be beneficial in ischemic stroke [21]. The neurotrophic factors, including hepatocyte growth factor (HGF), vascular endothelial growth factor (VEGF), brainderived neurotrophic factor (BDNF), basic fibroblast growth factor (bFGF), and insulin growth factor-1 (IGF-1), exert several protective effects, such as angiogenesis, neurogenesis, neuroprotection, and synaptogenesis [19].

BMSCs have the potential to be differentiated into mesenchymal lineages, neurons, and glial cells [22]. They can express neural or glial protein markers and take place of dying cells in the ischemic brain after treatment of stroke 
with BMSCs in animal experiments [23]. Some studies demonstrate that transplanted BMSCs can also differentiate into vascular endothelial cells in ischemic brain $[24,25]$.

The immunomodulatory function is also considered to account for the beneficial effects of BMSCs. BMSCs have a profound inhibitory effect on T-cell proliferation of inflammatory state, which modulate an immune response by inhibiting antigen-specific T-cell proliferation and cytotoxicity [26]. The underlying mechanisms of immunosuppressive effect of BMSCs involve several soluble molecules such as nitric oxide, indoleamine 2,3-dioxygenase, transforming growth factor- $\beta 1$ (TGF- $\beta 1$ ), HGF, interleukin- (IL-) 10, IL-6, and soluble HlA-G5, which are partially understood [27-29].

\section{Ischemic Stroke}

In the acute phase after stroke, ischemic injury is a following step through BBB breakdown, neuronal damage, and astrocytes activation [30-32]. Increased BBB permeability starts $2 \mathrm{~h}$ after the onset of ischemia; the dissolution of endothelial basal lamina may result from accumulation of vascular endothelial growth factor, active matrix metalloproteinases, and other protease activities following neurons, glia, and endothelial cells injury [33-36]. The second phase of severe BBB injury occurs within $24-72 \mathrm{~h}$ after ischemic stroke [37]. This stage is characterized with leukocyte infiltration and danger-associated molecular patterns (DAMPs) released from the necrotic brain to activate infiltrating immune cells [38].

High mobility group box 1 (HMGB1), a kind of DAMPs, is localized in cell nuclei in the normal brain. It can translocate into the cytosol and extracellular space after ischemic stroke [39]. Release of HMGB1 is observed 2-4 h after stroke onset and peaks around 4 days by activated microglia and astrocytes [40, 41]. Extracellular HMGB1 can bind to its receptors and activate downstream proinflammatory molecules such as TNF- $\alpha$, IL-1 $\beta$, MMP9, and RAGE [42-46]. The increased expression of these proinflammatory molecules contributes to $\mathrm{BBB}$ disruption, facilitates immune cell migration, and forms signaling complexes in the ischemic brain [47]. Blockade of HMGB1 mediated inflammatory signaling during the acute phase of stroke is beneficial for BBB functional integrity and functional recovery $[21,46,48]$.

\section{The Effects of BMSCs on Cerebral Ischemia}

Damaged brain can be surprisingly plastic and crosstalk between various types of remodeling in ischemic brain occurs after stroke [49]. Angiogenesis is defined as the formation of new capillaries from preexisting vessels through the activation of hypoxia inducible factor- $1 \alpha$ and proangiogenic molecules such as vascular endothelial growth factor-A (VEGF-A) and VEGF receptor-2 (VEGFR-2), angiopoietins (Ang-1 and Ang-2), cognate receptor Tie-2, neuropilin-1, and basic fibroblast growth factor [21, 50-52]. Ang-1 plays a vital role in recruiting pericytes and basement membrane deposition to inhibit endothelial cell migration, keep vascular stability, and form tube-like structures. However, Ang-2 acts as an antagonist for Ang-1 and balances the neovascularization procession [51]. Our previous study indicated that proand antiangiogenic factors play a vital role in the procession of angiogenesis after ischemic stroke. Enhanced secretion of angiogenic cytokines after treatment with BMSCs in ischemic stroke has strong angiogenic effects on microvasculature remodeling in neovascularization [53].

In the past decade, it was claimed that BMSCs treatment not only exerts angiogenic effects, but also induces neurogenesis, axonal sprouting, and neurite outgrowth after stroke [54]. Several possible mechanisms, involved in BMSCsinduced neuroprotective effects, are as follows. On the one hand, BMSCs treatment can induce the generation of new neurons from progenitor cells within the subventricular zone (SVZ) of the lateral ventricle and the dentate gyrus in ischemic brain $[22,55]$. On the other hand, BMSCs can enhance neurogenesis, oligodendrogenesis, and synaptogenesis by differentiating into neurons and oligodendrocyte [56].

\section{BMSCs Treatment of Ischemic Stroke in Aged Animals}

Age is the principal nonmodifiable risk factor for stroke [57]. Studies have shown that the rates of functional impairment and mortality were significantly increased in aged stroke patients when compared to relative young ones [58-62]. Studies have shown that the proliferation of endogenous neural precursor cells (NPCs) was significantly increased in the SVZ after BMSCs treatment in aged stroke animals $[63,64]$. Recently, BMSCs treatment of stroke has also shown to ameliorate neurological impairment in aged stroke rats by reducing infarction volume and promoting angiogenesis, neurogenesis, and synaptogenesis [65].

\section{BMSCs Treatment in Diabetic Stroke}

Diabetes mellitus (DM), as a global health problem complicated with microvascular and macrovascular diseases, is a predisposing risk factor for stroke. Stroke in diabetic patients has a higher mortality and worse outcomes after stroke [6668]. Previous study indicates that type 1 diabetic rats exhibited increased mortality and BBB leakage and reduced functional recovery when compared to nondiabetic individuals [69]. The poor outcomes after stroke in type 1 diabetic rats have been attributed to HMGB1 mediated inflammatory response and Ang1 regulated angiogenesis [70, 71].

BMSCs treatment of stroke has also been reported to contribute to increased dysfunctional angiogenesis and the risk of cerebral hemorrhage after stroke in type 1 diabetic rats [72-75]. This dysfunctional angiogenesis was associated with reduced functional recovery and vessel wall maturity, increased mortality rate, BBB leakage, and brain hemorrhage after diabetic stroke $[11,76]$.

\section{Administration Strategies of BMSCs}

Behavioral improvements after treatments of stroke with BMSCs have been observed with intracerebral, intracerebroventricular, and intravascular deliveries of stem/progenitor 
cells. Here we discuss the pros and cons of different delivery strategies.

Intracerebral and intracerebroventricular injections result in more transplanted cells in the infarcted region when compared to other delivery routes. However, the procedural risk for injection significantly raises safety issues [77, 78]. Until now, intracerebroventricular injection has been used only in one clinical trial. The study showed some patients developed fever and meningeal signs after cell implant via intracerebroventricular delivery [79]. Intravascular injection is another strategy to deliver BMSCs in stroke animals and patients. This strategy has several advantages, including easy injection and potential for widespread BMSCs distribution [80]. However, intravascular routes also have safety problems. BMSCs may stick together and cause microemboli, including lethal pulmonary emboli and microstrokes [80].

In conclusion, each cell delivery method has its pros and cons. Stroke subtype and cell delivery timing and working mechanisms should be taken into consideration together with the selection of cell delivery route.

\section{Therapeutic Time Window}

The optimal time for BMSCs delivery may be dependent on their mechanism of action. If a treatment focuses on neuroprotective mechanisms, acute delivery will be very important. If BMSCs aim to enhance endogenous repair mechanisms, then subacute transplantation would be optimum as these events are more prevalent in the first few weeks after stroke [81]. The route of administration may also affect the timing of transplantation. Because inflammatory signals may guide BMSCs home to the ischemic brain, intravascular injection may require early administration $[71,82]$. In conclusion, how the timing of administration affected the outcome of these trials is not clear, but they at least demonstrate that delivery of cells at different times is feasible.

\section{Conclusion}

Taken together, although tPA is the only approved treatment for acute ischemic stroke, cell-based therapy, especially BMSCs-based therapy, has also been shown to enhance function recovery, ameliorate cognitive dysfunction, and improve neuroplasticity after stroke. Many factors including nonmodifiable and modifiable risk factors such as age and diabetes may affect the efficiency of BMSCs treatment of stroke. Further investigations into the use of BMSCs as a therapeutic agent for the treatment of stroke are warranted.

\section{Disclosure}

Xinchun Ye and Jinxia Hu are co-first authors.

\section{Competing Interests}

The authors declare that they have no competing interests.

\section{Acknowledgments}

This work was supported by the National Natural Science Foundation of China (nos. 81201025 and 81571155), the National Natural Science Foundation of Jiangsu Province (nos. BK20131118 and BL2014031), and the Summit of Six Top Talents Program of Jiangsu Province (no. 2013-WSN-081).

\section{References}

[1] D. Mozaffarian, E. J. Benjamin, A. S. Go et al., "Heart disease and stroke statistics-2015 update : a report from the American Heart Association," Circulation, vol. 131, no. 4, pp. e29-e39, 2015.

[2] J. Liu, X. Jin, K. J. Liu, and W. Liu, "Matrix metalloproteinase2-mediated occludin degradation and caveolin-1-mediated claudin-5 redistribution contribute to blood-brain barrier damage in early ischemic stroke stage," Journal of Neuroscience, vol. 32, no. 9, pp. 3044-3057, 2012.

[3] J. Chen, Z. G. Zhang, Y. Li et al., "Statins induce angiogenesis, neurogenesis, and synaptogenesis after stroke," Annals of Neurology, vol. 53, no. 6, pp. 743-751, 2003.

[4] J. Chen, X. Cui, A. Zacharek et al., "Niaspan increases angiogenesis and improves functional recovery after stroke," Annals of Neurology, vol. 62, no. 1, pp. 49-58, 2007.

[5] B. J. Wu, L. Yan, F. Charlton, P. Witting, P. J. Barter, and K.-A. Rye, "Evidence that niacin inhibits acute vascular inflammation and improves endothelial dysfunction independent of changes in plasma lipids," Arteriosclerosis, Thrombosis, and Vascular Biology, vol. 30, no. 5, pp. 968-975, 2010.

[6] J. Zhang and M. Chopp, "Cell-based therapy for ischemic stroke," Expert Opinion on Biological Therapy, vol. 13, no. 9, pp. 1229-1240, 2013.

[7] M. Song, O. Mohamad, X. Gu, L. Wei, and S. P. Yu, "Restoration of intracortical and thalamocortical circuits after transplantation of bone marrow mesenchymal stem cells into the ischemic brain of mice," Cell Transplantation, vol. 22, no. 11, pp. 20012015, 2013.

[8] H. Xin, Y. Li, L. H. Shen et al., "Increasing tPa activity in astrocytes induced by multipotent mesenchymal stromal cells facilitate neurite outgrowth after stroke in the mouse," PLoS ONE, vol. 5, no. 2, Article ID e9027, 2010.

[9] S. Ishizaka, N. Horie, K. Satoh, Y. Fukuda, N. Nishida, and I. Nagata, "Intra-arterial cell transplantation provides timingdependent cell distribution and functional recovery after stroke," Stroke, vol. 44, no. 3, pp. 720-726, 2013.

[10] M. Gutiérrez-Fernández, B. Rodríguez-Frutos, J. Alvarez-Grech et al., "Functional recovery after hematic administration of allogenic mesenchymal stem cells in acute ischemic stroke in rats," Neuroscience, vol. 175, pp. 394-405, 2011.

[11] A. Rosell, A. Morancho, M. Navarro-Sobrino et al., "Factors secreted by endothelial progenitor cells enhance neurorepair responses after cerebral ischemia in mice," PLoS ONE, vol. 8, no. 9, Article ID e73244, 2013.

[12] Q. Zhao, J. Hu, J. Xiang et al., "Intranasal administration of human umbilical cord mesenchymal stem cells-conditioned medium enhances vascular remodeling after stroke," Brain Research, vol. 1624, pp. 489-496, 2015.

[13] A. J. Friedenstein, R. K. Chailakhjan, and K. S. Lalykina, "The development of fibroblast colonies in monolayer cultures of guinea-pig bone marrow and spleen cells," Cell and Tissue Kinetics, vol. 3, no. 4, pp. 393-403, 1970. 
[14] S. Law and S. Chaudhuri, "Mesenchymal stem cell and regenerative medicine: regeneration versus immunomodulatory challenges," American Journal of Stem Cells, vol. 2, no. 1, pp. 22-38, 2013.

[15] D. S. Krause, N. D. Theise, M. I. Collector et al., "Multi-organ, multi-lineage engraftment by a single bone marrow-derived stem cell," Cell, vol. 105, no. 3, pp. 369-377, 2001.

[16] D. S. Krause, "Plasticity of marrow-derived stem cells," Gene Therapy, vol. 9, no. 11, pp. 754-758, 2002.

[17] E. H. Javazon, K. J. Beggs, and A. W. Flake, "Mesenchymal stem cells: paradoxes of passaging," Experimental Hematology, vol. 32, no. 5, pp. 414-425, 2004.

[18] D. Woodbury, E. J. Schwarz, D. J. Prockop, and I. B. Black, "Adult rat and human bone marrow stromal cells differentiate into neurons," Journal of Neuroscience Research, vol. 61, no. 4, pp. 364-370, 2000.

[19] J. Chen and M. Chopp, "Neurorestorative treatment of stroke: cell and pharmacological approaches," NeuroRx, vol. 3, no. 4, pp. 466-473, 2006.

[20] L. M. Buja and D. Vela, "Immunologic and inflammatory reactions to exogenous stem cells: implications for experimental studies and clinical trials for myocardial repair," Journal of the American College of Cardiology, vol. 56, no. 21, pp. 1693-1700, 2010.

[21] X. Chen, Y. Li, L. Wang et al., "Ischemic rat brain extracts induce human marrow stromal cell growth factor production," Neuropathology, vol. 22, no. 4, pp. 275-279, 2002.

[22] J. Sanchez-Ramos, S. Song, F. Cardozo-Pelaez et al., "Adult bone marrow stromal cells differentiate into neural cells in vitro," Experimental Neurology, vol. 164, no. 2, pp. 247-256, 2000.

[23] A. Hermann, M. Maisel, and A. Storch, "Epigenetic conversion of human adult bone mesodermal stromal cells into neuroectodermal cell types for replacement therapy of neurodegenerative disorders," Expert Opinion on Biological Therapy, vol. 6, no. 7, pp. 653-670, 2006.

[24] S. Wislet-Gendebien, G. Hans, P. Leprince, J.-M. Rigo, G. Moonen, and B. Rogister, "Plasticity of cultured mesenchymal stem cells: switch from nestin-positive to excitable neuron-like phenotype," Stem Cells, vol. 23, no. 3, pp. 392-402, 2005.

[25] E. Pacary, H. Legros, S. Valable et al., "Synergistic effects of $\mathrm{CoCl}_{2}$ and ROCK inhibition on mesenchymal stem cell differentiation into neuron-like cells," Journal of Cell Science, vol. 119, no. 13, pp. 2667-2678, 2006.

[26] S. Aggarwal and M. F. Pittenger, "Human mesenchymal stem cells modulate allogeneic immune cell responses," Blood, vol. 105, no. 4, pp. 1815-1822, 2005.

[27] G. Kögler, T. F. Radke, A. Lefort et al., "Cytokine production and hematopoiesis supporting activity of cord blood-derived unrestricted somatic stem cells," Experimental Hematology, vol. 33, no. 5, pp. 573-583, 2005.

[28] Z. Selmani, A. Naji, I. Zidi et al., "Human leukocyte antigenG5 secretion by human mesenchymal stem cells is required to suppress T lymphocyte and natural killer function and to induce CD4+ CD25highFOXP3+ regulatory T cells," Stem Cells, vol. 26, no. 1, pp. 212-222, 2008.

[29] S. Suzuki, R. E. Kelley, Y. Reyes-Iglesias, V. M. Alfonso, and W. D. Dietrich, "Cerebrospinal fluid and peripheral white blood cell response to acute cerebral ischemia," Southern Medical Journal, vol. 88, no. 8, pp. 819-824, 1995.

[30] A. Shehadah, J. Chen, A. Zacharek et al., "Niaspan treatment induces neuroprotection after stroke," Neurobiology of Disease, vol. 40, no. 1, pp. 277-283, 2010.
[31] K. Hayakawa, L.-D. D. Pham, Z. S. Katusic, K. Arai, and E. H. Lo, "Astrocytic high-mobility group box 1 promotes endothelial progenitor cell-mediated neurovascular remodeling during stroke recovery," Proceedings of the National Academy of Sciences of the United States of America, vol. 109, no. 19, pp. 7505-7510, 2012.

[32] G. F. Hamann, Y. Okada, R. Fitridge, and G. J. del Zoppo, "Microvascular basal lamina antigens disappear during cerebral ischemia and reperfusion," Stroke, vol. 26, no. 11, pp. 2120-2126, 1995.

[33] A. Kastrup, T. Engelhorn, C. Beaulieu, A. de Crespigny, and M. E. Moseley, "Dynamics of cerebral injury, perfusion, and bloodbrain barrier changes after temporary and permanent middle cerebral artery occlusion in the rat," Journal of the Neurological Sciences, vol. 166, no. 2, pp. 91-99, 1999.

[34] J. M. Gidday, Y. G. Gasche, J.-C. Copin et al., "Leukocytederived matrix metalloproteinase- 9 mediates blood-brain barrier breakdown and is proinflammatory after transient focal cerebral ischemia," The American Journal of Physiology-Heart and Circulatory Physiology, vol. 289, no. 2, pp. H558-H568, 2005.

[35] Y. Gasche, J.-C. Copin, T. Sugawara, M. Fujimura, and P. H. Chan, "Matrix metalloproteinase inhibition prevents oxidative stress-associated blood-brain barrier disruption after transient focal cerebral ischemia," Journal of Cerebral Blood Flow and Metabolism, vol. 21, no. 12, pp. 1393-1400, 2001.

[36] M. Lorberboym, Y. Lampl, and M. Sadeh, "Correlation of ${ }^{99} \mathrm{~m}$ Tc-DTPA SPECT of the blood-brain barrier with neurologic outcome after acute stroke," Journal of Nuclear Medicine, vol. 44, no. 12, pp. 1898-1904, 2003.

[37] C. Iadecola and J. Anrather, "The immunology of stroke: from mechanisms to translation," Nature Medicine, vol. 17, no. 7, pp. 796-808, 2011.

[38] M. Passalacqua, M. Patrone, G. B. Picotti et al., "Stimulated astrocytes release high-mobility group 1 protein, an inducer of LAN-5 neuroblastoma cell differentiation," Neuroscience, vol. 82, no. 4, pp. 1021-1028, 1997.

[39] T. Bonaldi, F. Talamo, P. Scaffidi et al., "Monocytic cells hyperacetylate chromatin protein HMGB1 to redirect it towards secretion," The EMBO Journal, vol. 22, no. 20, pp. 5551-5560, 2003.

[40] K.-I. Kawahara, T. Hashiguchi, K. Kikuchi et al., "Induction of high mobility group box 1 release from serotonin-stimulated human umbilical vein endothelial cells," International Journal of Molecular Medicine, vol. 22, no. 5, pp. 639-644, 2008.

[41] J.-B. Kim, C.-M. Lim, Y.-M. Yu, and J.-K. Lee, "Induction and subcellular localization of high-mobility group box-1 (HMGB1) in the postischemic rat brain," Journal of Neuroscience Research, vol. 86, no. 5, pp. 1125-1131, 2008.

[42] G. Faraco, S. Fossati, M. E. Bianchi et al., "High mobility group box 1 protein is released by neural cells upon different stresses and worsens ischemic neurodegeneration in vitro and in vivo," Journal of Neurochemistry, vol. 103, no. 2, pp. 590-603, 2007.

[43] C. T. Ekdahl, Z. Kokaia, and O. Lindvall, "Brain inflammation and adult neurogenesis: the dual role of microglia," Neuroscience, vol. 158, no. 3, pp. 1021-1029, 2009.

[44] J. Qiu, M. Nishimura, Y. Wang et al., "Early release of HMGB1 from neurons after the onset of brain ischemia," Journal of Cerebral Blood Flow and Metabolism, vol. 28, no. 5, pp. 927-938, 2008. 
[45] S. Muhammad, W. Barakat, S. Stoyanov et al., "The HMGB1 receptor RAGE mediates ischemic brain damage," The Journal of Neuroscience, vol. 28, no. 46, pp. 12023-12031, 2008.

[46] M. E. Bianchi, "HMGB1 loves company," Journal of Leukocyte Biology, vol. 86, no. 3, pp. 573-576, 2009.

[47] X. Ye, M. Chopp, X. Liu et al., "Niaspan reduces high-mobility group box 1/receptor for advanced glycation endproducts after stroke in type-1 diabetic rats," Neuroscience, vol. 190, pp. 339$345,2011$.

[48] J. Qiu, J. Xu, Y. Zheng et al., "High-mobility group box 1 promotes metalloproteinase- 9 upregulation through toll-like receptor 4 after cerebral ischemia," Stroke, vol. 41, no. 9, pp. 2077-2082, 2010

[49] R. Blanco and H. Gerhardt, "VEGF and Notch in tip and stalk cell selection," Cold Spring Harbor Perspectives in Medicine, vol. 3, no. 1, Article ID a006569, 2013.

[50] P. Carmeliet and R. K. Jain, "Molecular mechanisms and clinical applications of angiogenesis," Nature, vol. 473, no. 7347, pp. 298307, 2011.

[51] B. Han, Q. Wang, G. Cui, X. Shen, and Z. Zhu, "Posttreatment of Bax-inhibiting peptide reduces neuronal death and behavioral deficits following global cerebral ischemia," Neurochemistry International, vol. 58, no. 2, pp. 224-233, 2011.

[52] B. Xu, Y. Luo, Y. Liu, B. Li, and Y. Wang, "Platelet-derived growth factor-BB enhances MSC-mediated cardioprotection via suppression of miR-320 expression," American Journal of Physiology-Heart and Circulatory Physiology, vol. 308, no. 9, pp. H980-H989, 2015.

[53] M. Sasaki, C. Radtke, A. M. Tan et al., "BDNF-hypersecreting human mesenchymal stem cells promote functional recovery, axonal sprouting, and protection of corticospinal neurons after spinal cord injury," Journal of Neuroscience, vol. 29, no. 47, pp. 14932-14941, 2009.

[54] M. B. Luskin, T. Zigova, B. J. Soteres, and R. R. Stewart, "Neuronal progenitor cells derived from the anterior subventricular zone of the neonatal rat forebrain continue to proliferate in vitro and express a neuronal phenotype," Molecular and Cellular Neuroscience, vol. 8, no. 5, pp. 351-366, 1997.

[55] C. Suárez-Monteagudo, P. Hernández-Ramírez, L. ÁlvarezGonzález et al., "Autologous bone marrow stem cell neurotransplantation in stroke patients. An open study," Restorative Neurology and Neuroscience, vol. 27, no. 3, pp. 151-161, 2009.

[56] Y. Qiu, J. Pan, Y. Li et al., "Relationship between activated astrocytes and hypoxic cerebral tissue in a rat model of cerebral ischemia/reperfusion," International Journal of Neuroscience, vol. 121, no. 1, pp. 1-7, 2011.

[57] I. Badan, B. Buchhold, A. Hamm et al., "Accelerated glial reactivity to stroke in aged rats correlates with reduced functional recovery," Journal of Cerebral Blood Flow and Metabolism, vol. 23, no. 7, pp. 845-854, 2003.

[58] B. Buchhold, L. Mogoanta, Y. Suofu et al., "Environmental enrichment improves functional and neuropathological indices following stroke in young and aged rats," Restorative Neurology and Neuroscience, vol. 25, no. 5-6, pp. 467-484, 2007.

[59] A. Popa-Wagner, S. T. Carmichael, Z. Kokaia, C. Kessler, and L. C. Walker, "The response of the aged brain to stroke: too much, too soon?" Current Neurovascular Research, vol. 4, no. 3, pp. 216-227, 2007.

[60] A. Popa-Wagner, M. Filfan, A. Uzoni, P. Pourgolafshan, and A. M. Buga, "Poststroke cell therapy of the aged brain," Neural Plasticity, vol. 2015, Article ID 839638, 7 pages, 2015.
[61] A. Popa-Wagner, A.-M. Buga, T. R. Doeppner, and D. M. Hermann, "Stem cell therapies in preclinical models of stroke associated with aging," Frontiers in Cellular Neuroscience, vol. 8, article 347, 2014.

[62] A. T. Balseanu, A.-M. Buga, B. Catalin et al., "Multimodal approaches for regenerative stroke therapies: combination of granulocyte colony-stimulating factor with bone marrow mesenchymal stem cells is not superior to G-CSF alone," Frontiers in Aging Neuroscience, vol. 6, article 130, 2014.

[63] T. Kojima, Y. Hirota, M. Ema et al., "Subventricular zonederived neural progenitor cells migrate along a blood vessel scaffold toward the post-stroke striatum," Stem Cells, vol. 28, no. 3, pp. 545-554, 2010.

[64] J. Walter, S. Keiner, O. W. Witte, and C. Redecker, "Differential stroke-induced proliferative response of distinct precursor cell subpopulations in the young and aged dentate gyrus," Neuroscience, vol. 169, no. 3, pp. 1279-1286, 2010.

[65] H. Mast, J. L. P. Thompson, S.-H. Lee, J. P. Mohr, and R. L. Sacco, "Hypertension and diabetes mellitus as determinants of multiple lacunar infarcts," Stroke, vol. 26, no. 1, pp. 30-33, 1995.

[66] P. Ghosh, R. Sahoo, A. Vaidya, M. Chorev, and J. A. Halperin, "Role of complement and complement regulatory proteins in the complications of diabetes," Endocrine Reviews, vol. 36, no. 3, pp. 272-288, 2015.

[67] S. E. Capes, D. Hunt, K. Malmberg, P. Pathak, and H. C. Gerstein, "Stress hyperglycemia and prognosis of stroke in nondiabetic and diabetic patients: a systematic overview," Stroke, vol. 32, no. 10, pp. 2426-2432, 2001.

[68] W. Li, R. Prakash, A. I. Kelly-Cobbs et al., "Adaptive cerebral neovascularization in a model of type 2 diabetes: relevance to focal cerebral ischemia," Diabetes, vol. 59, no. 1, pp. 228-235, 2010.

[69] X. Ye, M. Chopp, X. Cui et al., "Niaspan enhances vascular remodeling after stroke in type 1 diabetic rats," Experimental Neurology, vol. 232, no. 2, pp. 299-308, 2011.

[70] Y. Okuno, A. Nakamura-Ishizu, K. Otsu, T. Suda, and Y. Kubota, "Pathological neoangiogenesis depends on oxidative stress regulation by ATM," Nature Medicine, vol. 18, no. 8, pp. 1208-1216, 2012.

[71] J. Chen, X. Ye, T. Yan et al., "Adverse effects of bone marrow stromal cell treatment of stroke in diabetic rats," Stroke, vol. 42, no. 12, pp. 3551-3558, 2011.

[72] D. Watanabe, K. Suzuma, I. Suzuma et al., "Vitreous levels of angiopoietin 2 and vascular endothelial growth factor in patients with proliferative diabetic retinopathy," American Journal of Ophthalmology, vol. 139, no. 3, pp. 476-481, 2005.

[73] S. K. Kota, L. K. Meher, S. Jammula, S. K. Kota, S. V. Krishna, and K. D. Modi, "Aberrant angiogenesis: the gateway to diabetic complications," Indian Journal of Endocrinology and Metabolism, vol. 16, no. 6, pp. 918-930, 2012.

[74] A. Ergul, M. Abdelsaid, A. Y. Fouda, and S. C. Fagan, "Cerebral neovascularization in diabetes: implications for stroke recovery and beyond," Journal of Cerebral Blood Flow and Metabolism, vol. 34, no. 4, pp. 553-563, 2014.

[75] Y.-N. Li, R. Pan, X.-J. Qin et al., "Ischemic neurons activate astrocytes to disrupt endothelial barrier via increasing VEGF expression," Journal of Neurochemistry, vol. 129, no. 1, pp. 120129, 2014.

[76] J.-Y. Hsieh, H.-W. Wang, S.-J. Chang et al., "Mesenchymal stem cells from human umbilical cord express preferentially secreted factors related to neuroprotection, neurogenesis, and angiogenesis," PLoS ONE, vol. 8, no. 8, Article ID e72604, 2013. 
[77] A. Moisan, N. Pannetier, E. Grillon et al., "Intracerebral injection of human mesenchymal stem cells impacts cerebral microvasculature after experimental stroke: MRI study," NMR in Biomedicine, vol. 25, no. 12, pp. 1340-1348, 2012.

[78] E. J. Smith, R. P. Stroemer, N. Gorenkova et al., "Implantation site and lesion topology determine efficacy of a human neural stem cell line in a rat model of chronic stroke," STEM CELLS, vol. 30, no. 4, pp. 785-796, 2012.

[79] S. S. Rabinovich, V. I. Seledtsov, N. V. Banul et al., "Cell therapy of brain stroke," Bulletin of Experimental Biology and Medicine, vol. 139, no. 1, pp. 126-128, 2005.

[80] V. Misra, M. M. Ritchie, L. L. Stone, W. C. Low, and V. Janardhan, "Stem cell therapy in ischemic stroke: role of IV and intraarterial therapy," Neurology, vol. 79, no. 13, supplement 1, pp. S207-S212, 2012.

[81] S. T. Carmichael, "Cellular and molecular mechanisms of neural repair after stroke: making waves," Annals of Neurology, vol. 59, no. 5, pp. 735-742, 2006.

[82] X. Ye, T. Yan, M. Chopp et al., "Combination BMSC and Niaspan treatment of stroke enhances white matter remodeling and synaptic protein expression in diabetic rats," International Journal of Molecular Sciences, vol. 14, no. 11, pp. 22221-22232, 2013. 


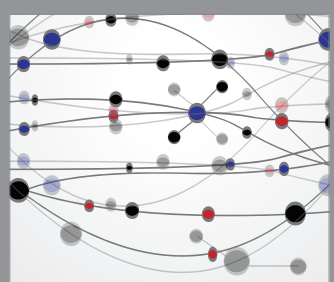

The Scientific World Journal
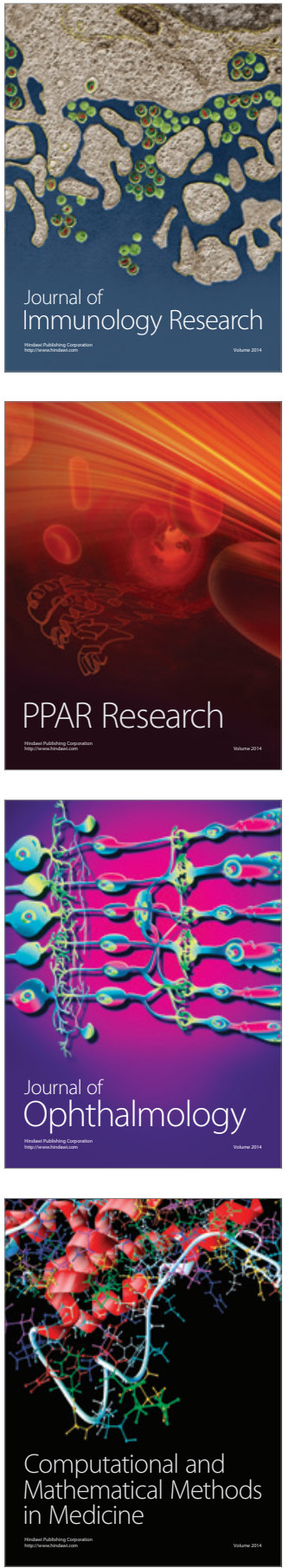

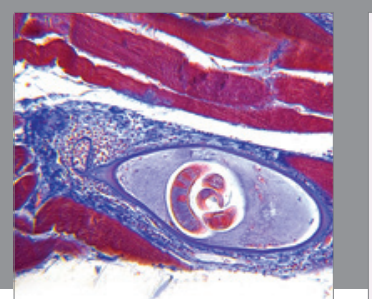

Gastroenterology Research and Practice

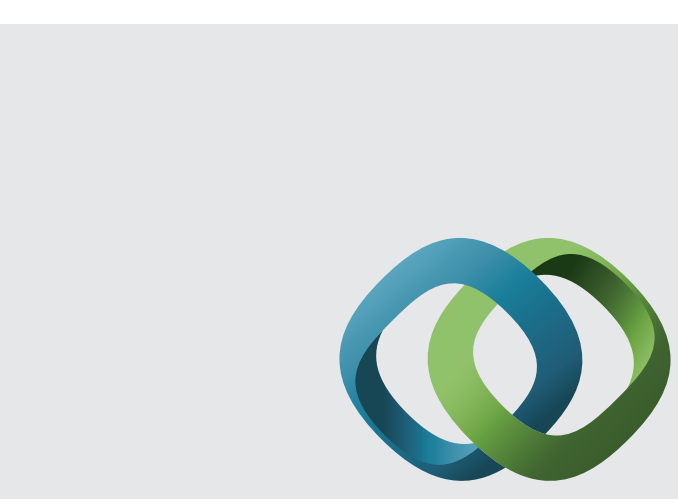

\section{Hindawi}

Submit your manuscripts at

http://www.hindawi.com
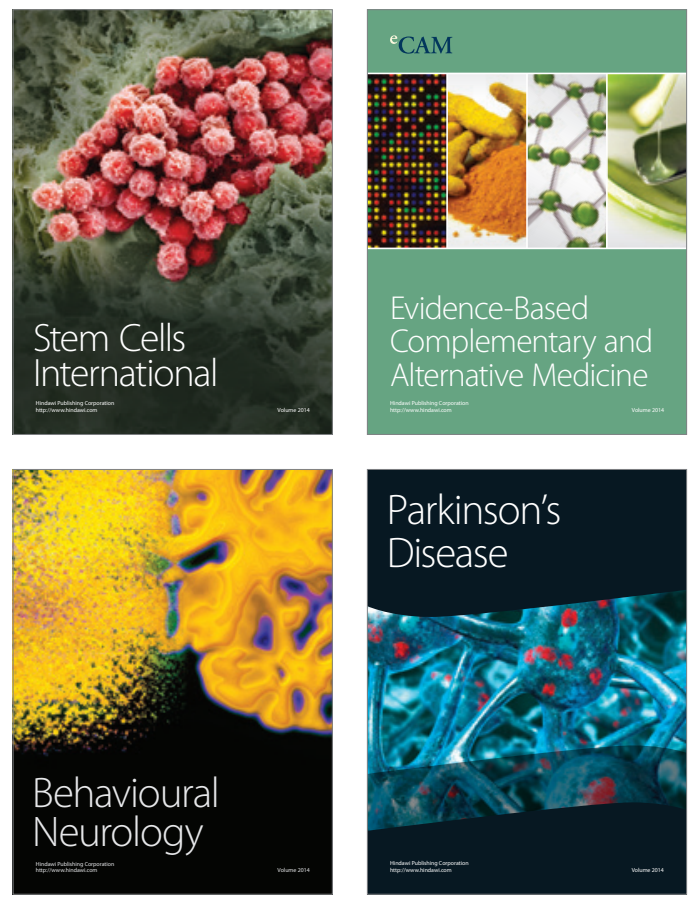
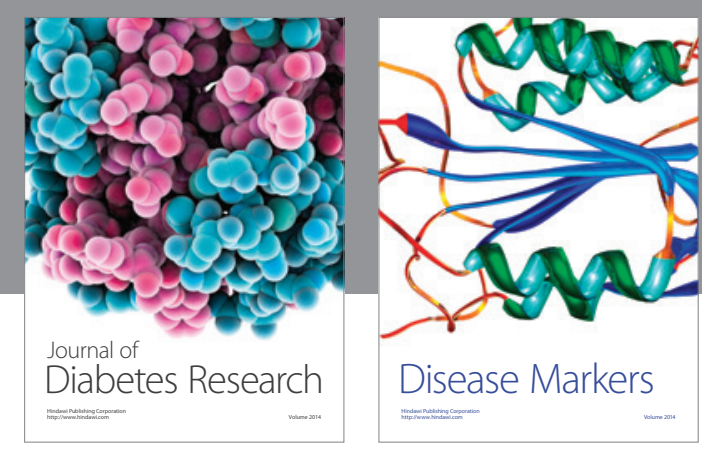

Disease Markers
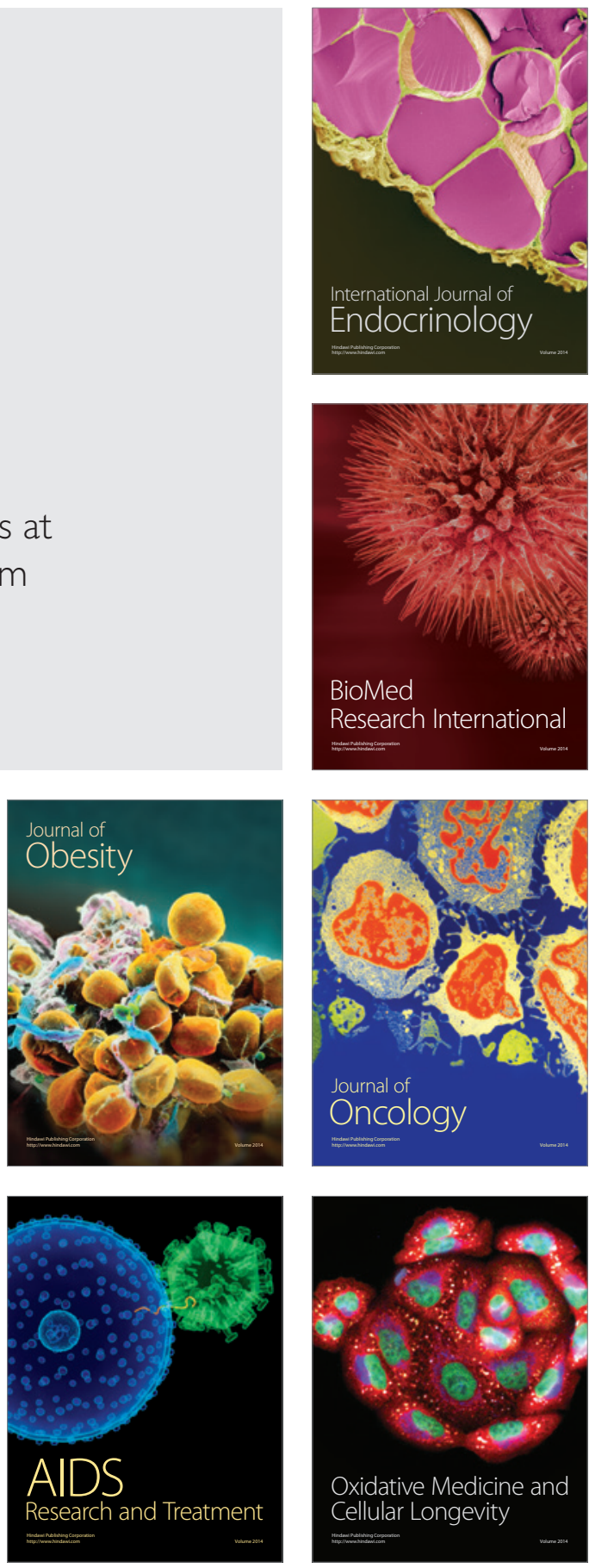